\title{
An overview of allergy and sinusitis
}

\author{
Nicholus Magongwa, Natalie Schellack* \\ School of Pharmacy, Faculty of Health Sciences, Sefako Makgatho Health Sciences University
}

*Corresponding author, email: natalie.schellack@smu.ac.za

\begin{abstract}
Allergic diseases affect many people across the globe. They are considered to significantly disturb the quality of life of the people who are affected, creating personal and economic predicaments. Some of the most commonly diagnosed allergic diseases include atopic dermatitis, rhinitis, allergic conjunctivitis and sinusitis. Some conditions, such as eosinophilic esophagitis, are on the rise and are being diagnosed across all continents except for Africa. The use of antihistamines has been the mainstay of therapy for most allergic conditions, except for other conditions that require corticosteroids, or in severe allergic conditions such as anaphylaxis where antihistamines are ineffective as main therapy. It is important to consider first versus second-generation options when treating allergic diseases, also bearing in mind the duration of therapy and any comorbid conditions that a patient might have. This article provides an overview of these conditions and their current management options.
\end{abstract}

Keywords: allergic disease, antihistamine, anaphylaxis, atopy, atopic march, rhinitis, sinusitis

\section{Introduction}

Allergic diseases are complex diseases caused by a combination of genetic and environmental factors. Allergic diseases are on the increase, affecting approximately $30 \%$ to $40 \%$ of the world's population. They decrease quality of life and may have an immense influence on personal, social, and economic costs. ${ }^{1}$

An allergic response is a hypersensitivity reaction mediated by the adaptive immune system. The presence of a trigger, such as an allergen or antigen, induces a humoral immunological response, which in turn initiates a complex immunological reaction. This dysregulation in the immune function elevates the plasma levels of immunoglobulin $\mathrm{E}(\mathrm{IgE})$. The release of $\lg \mathrm{E}$ is followed by binding to the allergen or antigen, which in turn stimulates the mast cells to degranulate and release several proinflammatory substances that include histamine, chemokines and numerous cytokines. ${ }^{2}$

There are many different factors that come into play when searching for the causative agent of allergy. Environmental influences that occur in pregnancy and early childhood can alter the physiologic, immune, structural and behavioral development and thus transform response patterns that influence susceptibility to future diseases. ${ }^{3}$ Genetics also play a vital role in the susceptibility of an individual to an allergic disease. The most common allergic conditions around the world include, atopic dermatitis, rhinitis, asthma, rhinosinusitis, allergic conjunctivitis and, most recently, allergic oesophagitis. ${ }^{3,4}$

\section{The atopic march}

Atopy refers to the increased sensitivity of $\lg E$ to a specific antigen, which in turn, results in a hypersensitive response upon exposure toward the specific allergen in question. ' 'Atopic march' is a term that refers to the development of various atopic diseases that may develop during childhood. The atopic march may also refer to how the sequence of clinical symptoms and atopic disease manifest during childhood growth and development. ${ }^{6}$ The initial development of atopy has been linked to various predisposing risk factors. These include a genetic predisposition, decreased exposure to infections and endotoxins, postnatal antibiotic use, obesity, tobacco smoke, air pollutants, exposure to allergens, maternal weight gain or obesity, gestational use of antibiotics and maternal stress. ${ }^{7}$

\section{Pathophysiology of atopy}

There is vast evidence that shows that T-lymphocytes play a major role in allergic diseases. The T-helper cell type 1 (Th1)/ T-helper cell type 2 (Th2) paradigm has been extensively studied and seems to be the major pathological pathway in allergic diseases. The paradigm explains the relationship between the Th1 and Th2 subsets of the T lymphocyte. Th1 and Th2 subsets tend to differentiate from CD4+-naïve $T$ lymphocytes. This means that whenever a raised response towards either the Th1 or the Th2 subset occurs, the other will be reduced. ${ }^{8}$ When there is a reduction in Th1 production, there is observed decreased levels of interferon gamma (IFN-g), interleukin (IL)-2 and tumour necrosis factor (TNF)-beta. This in turn leads to elevated levels 
of Th2 effect, owing to a decrease in Immunoglobulin G (IgG) production, which inhibits Th2 formation. ${ }^{8,9}$

Figure 1 shows the imbalance in Th1 and Th2 that leads to atopic diseases. ${ }^{9}$

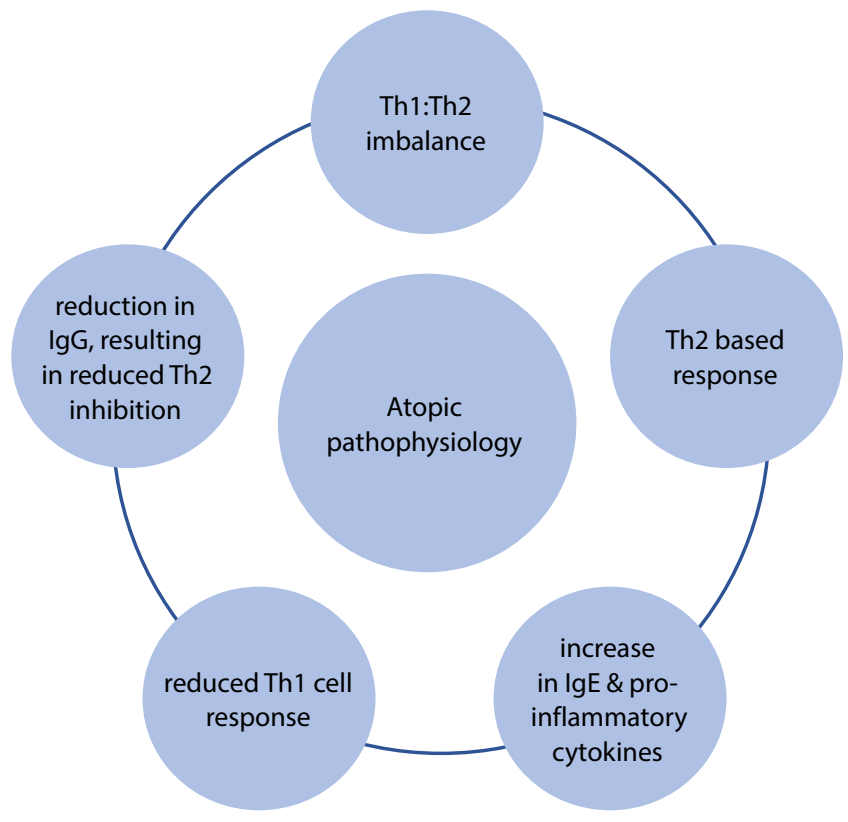

Figure 1: The imbalance between Th1 and Th2.

lgG: immunoglobulin G, Th1:T-helper cell type 1, Th2: T-helper cell type 1

\section{The role of histamine in allergy}

Histamine is an endogenous substance synthesized from histidine. It has the ability to elicit autacoid effects within peripheral tissues and also act as a neurotransmitter within the central nervous system (CNS)..$^{10}$ The role of histamine in the inflammatory process remains significant in understanding the pathophysiology thereof. The release of histamine in peripheral tissue areas is mediated by mast cell degranulation. This degranulation can be triggered in various ways. In allergic diseases, an interaction between $\lg \mathrm{E}$ (immunoglobulin $\mathrm{E}$ ) antibodies and suitable $\mathrm{lgE}$ antigens (i.e. the formation of antigen-antibody complexes) that causes allergic reactions (localized histamine release) or anaphylaxis (systemic histamine release), seems to be the major trigger. ${ }^{10}$

There are currently four identified histaminergic receptor subtypes (i.e. the $\mathrm{H}_{1}$ to $\mathrm{H}_{4}$-receptors). The $\mathrm{H}_{1}$-receptor is the main active subtype in mediating acute allergic reactions. There are different effects that may be induced by $\mathrm{H}_{1}$-receptor stimulation. Some of these effects lead to allergic conditions, which include allergic rhinitis and conjunctivitis, urticaria, pruritus and angioneurotic oedema. ${ }^{10}$

Stimulation of these receptors is also responsible for the vasodilatation and the increased vascular (capillary) permeability that accompany allergic reactions and inflammation. Erythema and oedema, including potentially fatal glottis oedema. Understanding histamine regulation assists in the type of treatment to be initiated in various allergic reactions. For instance, histamine is released systemically in anaphylaxis but the use of an antihistamine alone is not effective in treating anaphylaxis. ${ }^{10}$

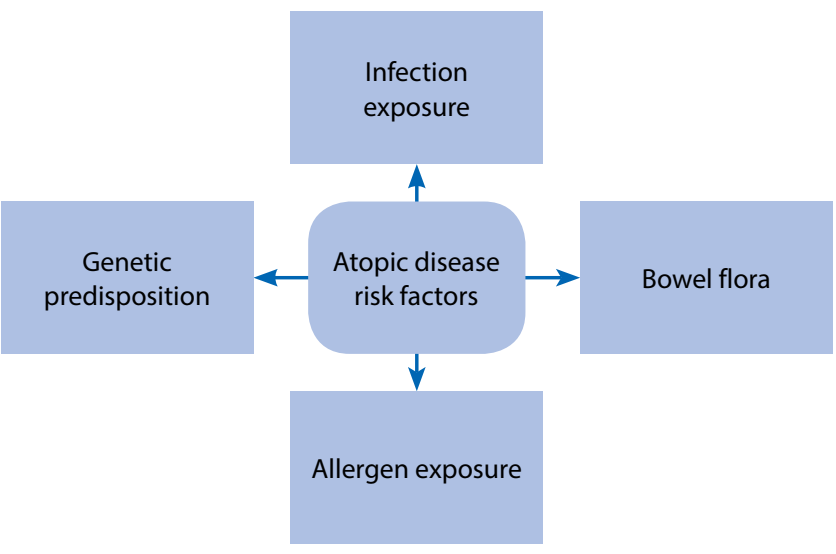

Figure 2: Risk factors of developing atopy. ${ }^{2}$

\section{Genetic predisposition}

Allergies tend to be familial, with patients who suffer from an allergy tending to have an increased risk of having children with some form of atopy. ${ }^{2}$ There is vast evidence that shows that $\mathrm{T}$ lymphocytes play a major role in allergic diseases. Several studies have looked at the role of genetics in allergic diseases. Some studies have had mitochondrial RNA (miRNA) as the main focus of such investigations. The earlier studies have shown that several types of miRNA augment the sensitivity of T cells to peptide antigens. Evidence suggests that inhibition of miR-181a expression in immature $T$ cells significantly decreases sensitivity to antigens and enhances the impairment of T-cell selection. T-cell apoptosis is crucial in regulating both the length and strength of T-cell responses. MiR-21 has also been extensively studied, showing significant upregulation during T-cell activation and plays a role in the suppression of apoptosis in activated T cells. It is therefore essential to understand the role of various miRNA in T-cell regulation as the development of polarized TH cells is central to the pathogenesis of allergic inflammation because allergic inflammation is predominately a $\mathrm{TH} 2$ response. ${ }^{11}$

\section{Allergen exposure}

Exposure to an allergen in individuals with an atopic disease increases the risk of developing a hypersensitivity reaction, regardless of the level of antigen exposure. The evidence showing that immune sensitization is not dependent on the level of allergen exposure gives credibility towards a belief that the existence of atopic disease is hereditary. On the contrary, some studies suggest that low levels of allergen exposure are not sufficient to produce a response, while high levels of allergen exposure induce tolerance toward that allergen, i.e. desensitizing it. ${ }^{12}$

\section{Infections and endotoxin exposure}

The hygiene hypothesis is applicable to most atopic diseases. It predicts that the prevalence of atopic diseases is decreased when a child is exposed to more infectious agents. It is estimated that the exposure to animals, viruses, bacteria and various endotoxins makes children less likely to develop an atopic disease. The 
hygiene hypothesis emerges from the understanding that bacterial, viral and endotoxin factors trigger an immune response of Th1 lymphocytes. Th1 lymphocytes increase the production of IgG antibodies. Th1 (through lgG) indirectly suppresses the activity of Th2 which mediates the release of various cytokines including IgE. These Th2 cytokines are common culprits in the development of allergic diseases. ${ }^{2,6,13,14}$

\section{Intestinal flora}

The presence of microbes in the walls of the intestinal tract helps to regulate an immune response. Exposure to microbial flora, within the gastrointestinal tract, early in life allows for a change in the Th1:Th2 cytokine balance, favoring a Th1cell response. $A$ shift in the microbial balance initiates a change in immune response. ${ }^{2}$ The evidence then suggests that exposure to high dosages of antibiotics in early neonates may alter the composition of intestinal flora, leaning towards an immune response with elevated levels of Th2. The elevated Th2 leads to increased IgE production and therefore likelihood of developing an atopic disease. ${ }^{15}$

\section{Common allergic diseases across the globe}

Several allergic conditions are described in more detail below.

\section{Rhinitis}

Rhinitis is an inflammation of the nasal mucosa. According to the Australasian Society of Clinical Immunology and allergy (ASCIA, 2015), ${ }^{16}$ there are various causes of rhinitis which include: allergies (hay fever), increased sensitivity to irritants such as smoke, temperature changes or the overuse of decongestant nasal sprays. ${ }^{16}$ The most common antigens for allergic rhinitis are inhaled allergens, the most concerning being dust mites, animal dander and pollen. ${ }^{16,17}$

Allergic rhinitis (AR) affects approximately $20 \%$ of the world population and is considered to be the most common chronic disease. ${ }^{18} \mathrm{AR}$ is a type 1 allergic disease which reduces quality of life depending on the severity. ${ }^{19}$ Exposure to nasal allergens stimulate an IgE-mediated type 1 hypersensitivity reaction, resulting in symptomatic reactions to the allergen. The early characteristic symptoms of allergic rhinitis are rhinorrhea, nasal congestion and sneezing. ${ }^{18,19,20} \mathrm{AR}$ can also be associated with various conditions such as bronchial asthma, allergic conjunctivitis, rhinosinusitis and others. ${ }^{20}$

The inhalation of nasal antigens in sensitized individuals causes the antigens to pass through mucosal epithelial cells, binding to IgE antibodies on mast cells distributed over the nasal mucosa. The antigen-antibody complex stimulates an IgE-mast-cellmediated early-phase response. ${ }^{18}$ Chemical mediators, such as histamine and peptide leukotrienes (LTs), are released from mast cells. The release of these mediators cause irritation to the sensory nerve endings and mucosal blood vessels, leading to early phase reaction symptoms (i.e. sneezing, watery rhinorrhea, and nasal mucosal swelling). ${ }^{19}$ The early phase symptoms usually appear within 30 minutes after exposure to an allergen. Late-phase response results in tissue damage and remodeling, appearing 24 hours after allergen exposure. The presence of an antigen in the nasal mucosa leads to the stimulation of cytokines, chemical mediators and chemokines which respond by releasing various inflammatory cells, such as activated eosinophil which infiltrate into the nasal mucosa. Leukotrienes, produced by these inflammatory cells, cause nasal mucosal swelling. ${ }^{18,19}$

\section{Sinusitis}

Sinusitis is defined as inflammation of the paranasal sinus mucosa. Sinusitis has been replaced with the more correct term 'rhinosinusitis'.21 The term rhinosinusitis is given preference over sinusitis because sinusitis, in most instances, is almost always followed by inflammation of the adjacent nasal mucosa. The classification of rhinosinusitis is usually based on whether it is acute rhinosinusitis (ARS) or chronic rhinosinusitis (CRS). Many scientists concur on the duration of CRS being longer than 12 weeks while ARS still has different duration classifications from different scientists but usually less than 12 weeks. ${ }^{22}$

\section{Acute Rhinosinusitis}

Acute rhinosinusitis occurs as a result of inflammation of the nasal mucosa mainly due to bacterial, fungal, or viral infections, as well as allergies or exposure to inhaled irritants. ${ }^{23}$ It is essential to properly diagnostically distinguish bacterial ARS from viral ARS, to assist with the treatment plan. Treatment in bacterial ARS involves antibiotics which would be inappropriate if used for viral ARS. ${ }^{22,23}$

\section{Chronic rhinosinusitis}

Chronic rhinosinusitis affects about $10-15 \%$ of the adult population in industrialized countries such as Europe and the US, and is one of the most reported chronic conditions. ${ }^{24}$ It has been observed over the years that there are multiple variants of CRS which include characterization of the disease by chronic infection, non-eosinophilic inflammation, chronic hyperplastic eosinophilic sinusitis (CHES), aspirin-exacerbated respiratory disease and allergic fungal sinusitis. ${ }^{25}$ When there is chronic inflammation in the nasal mucosa, the observed result is mucosal swelling (including polyposis), increased mucus secretion, airway obstruction, and blocked sinus drainage. The inability of the nose to eliminate bacteria, viruses, fungi and allergens create an environment of chronic inflammation which then results in a chronic nasal disease. ${ }^{23}$ Some patients with chronic sinusitis present with massive submucosal eosinophilic infiltration. Eosinophilic sinusitis is characterized by multiple nasal polyps, viscous rhinorrhea, and olfactory disorder, and is often complicated by asthma. Eosinophilic sinusitis is extremely intractable and resistant to surgery, resulting in repeated relapses. Oral corticosteroid therapy often results in a complete response. ${ }^{19}$

\section{Allergic rhinosinusitis}

The presence of an allergen can cause inflammation of the sinus mucosa which may be acute or even chronic. This inflammation prevents the usual clearance of bacteria from the sinus cavity, increasing the chances of developing secondary bacterial 
sinusitis. It is estimated that more than $50 \%$ of people with allergic rhinosinusitis have clinical or radiographic evidence of CRS. About $25-58 \%$ of people with rhinosinusitis have some form of inhaled allergen sensitization. This is confirmed by the presence of raised $\mathrm{lgE}$, which leads to an active immune response. Evidence supports the suggestion that CRS could be an atopic disease driven by lgE sensitization to aeroallergens. ${ }^{25}$ The symptoms of Allergic rhinosinusitis include: rhinorrhea, nasal congestion, facial pain, fever, cough, sore throat and fatigue. ${ }^{26}$ These symptoms significantly reduce the quality of life of individuals, creating inconvenience for both people and the economy.

\section{Atopic Dermatitis}

Atopic dermatitis (AD) is one of the most common chronic inflammatory disorder of the skin with a strong link to genetic predisposing factors. It affects approximately $20 \%$ children and $1 \%-3 \%$ of adults in industrial countries. ${ }^{27}$ There is a clearly identified hyper-proliferative cutaneous disorder in $A D$ that is associated with a defective skin barrier and a mixed $\mathrm{TH} 1 /$ $\mathrm{TH} 2$ inflammatory response. This exposes the skin and makes it susceptible to cutaneous infections and moderate to severe pruritus. ${ }^{11}$ A major number of patients suffering from AD have been observed to have elevated serum levels of total $\operatorname{lgE}$ and allergen-specific $\lg \mathrm{E}$, with approximately $50 \%$ of the individuals testing positive from an atopy patch test. ${ }^{27}$ There are several allergens that lead to the exacerbation of $A D$ which may include airborne pathogens (e.g. pollen) and various food sources. Avoidance of identified allergens usually has significant benefit to patients with AD. 5,27

\section{Eosinophilic oesophagitis}

Eosinophilic oesophagitis is an allergic condition that has recently emerged and reported in all continents except Africa. ${ }^{11}$ Observed inflammation of the oesophagus with an abnormal eosinophils in allergic reaction is the main characteristic of the disease. Potential allergens include cross reacting molecules, which is common between pollen antigens or latex food allergens. The emergence and prevalence of this disease is becoming a global concern and requires more investigation. ${ }^{1,11,19}$

\section{Allergic conjunctivitis}

Allergic conjunctivitis is an inflammatory response of the conjunctivae to allergens such as pollen, environmental antigens (e.g. dust), and animal dander. ${ }^{28}$ Hyperemic conjunctivitis is a common type of conjunctivitis, most patients show symptoms of ocular itching, lacrimation, hyperemia, eye discharge, etc. Severe symptoms cause eyelid swelling. Steroids are usually the treatment agent of choice but they may elicit undesirable adverse effects such as glaucoma and corneal ulcer if used for a prolonged duration. ${ }^{19}$

\section{Asthma}

Asthma is one of the most common chronic inflammatory diseases that affect both children and adults. The inflammatory process causes hyper-responsiveness in the bronchial tree, with reversible airflow obstruction. Inflammation of the bronchial tree may result in airway constriction via smooth muscle contraction, the hyper-secretion of mucus, bronchial hyper-responsiveness, and additional narrowing of the airway due to mucosal oedema and sloughing of the epithelial cells. ${ }^{11}$

Allergic asthma is observed to be the most common type, caused mainly by inhaled allergens inducing an immune system response. ${ }^{11}$ The implementation of therapy must be done after accurate classification of asthma severity. This assists in reviewing the management of the condition when periodic assessment for asthma control has been established. Diagnosing asthma is based on two tools which are: identification of a characteristic pattern of respiratory symptoms and expiratory airflow limitation which vary according to each patient. ${ }^{29}$

\section{Management of allergic diseases}

Allergic diseases can be strategically managed both nonpharmacologically and pharmacologically. ${ }^{30}$ The use of pharmacological preparations is usually preferred for use when non-pharmacological methods prove ineffective or insufficient in alleviating the allergic symptoms. Different pharmaceutical preparations (systemic, intranasal, topical, etc.) are used depending on the symptoms and type of allergic disease..$^{28,30}$

\section{Local decongestants}

Local decongestants are mainly sympathomimetic drugs that stimulate $\alpha_{1}$-adrenergic receptors producing vasoconstriction. This in turn decreases mucosal oedema and local vasodilation..$^{30}$ Examples of the most commonly used drugs include xylometazoline, phenylephrine and oxymetazoline. ${ }^{31}$ Local decongestants are usually indicated to reduce acute symptoms as prolonged use can produce undesirable effects to the user. ${ }^{30}$ After persistent use (usually more than 5 days), rebound rhinitis and conjunctivitis medicamentosa start to appear. Oxymetazoline and xylometazoline have a long-acting effect on the $\alpha_{1}$-receptor, whereas phenylephrine has a shorter duration of action, lasting up to approximately four hours. ${ }^{32}$

\section{Systemic decongestants}

These agents stimulate $a_{1}$-receptors producing vasoconstriction, reducing oedema, redness and itching. Their preparations usually contain an antihistamine. It is important to note that combination therapy of a systemic decongestant and an oldertype $\mathrm{H}_{1}$-antihistamine can produce drowsiness and a lack of motor coordination. Systemic decongestants available in South Africa include pseudoephedrine, phenylpropanolamine and phenylephrine. The use of phenylpropanolamine has produced sub-arachnoid bleeding with a haemorrhagic stroke in women using it as an appetite suppressant. The total daily dosage of phenylpropanolamine should not exceed a $100 \mathrm{mg} .{ }^{30}$

\section{Corticosteroids}

Glucocorticosteroids can be used for various allergic conditions such as asthma, allergic rhinitis and minimal use in allergic conjunctivitis. They exert their pharmacological action by modifying protein synthesis through regulating 
transcription, and indirectly by modifying the activity or halflife of transcription factors and mRNA. The currently available intranasal corticosteroids include: beclomethasone, budesonide, fluticasone, mometasone, triamcinolone and ciclesonide. The newer agents, namely mometasone, fluticasone, and ciclesonide, are also administered intranasally and result in minimal systemic effects. ${ }^{31}$ The most common local side-effects experienced with the intranasal corticosteroids include dryness, stinging, burning, and epistaxis. Chronic use of topical corticosteroids may lead to atrophy of the nasal mucosa. It is therefore advisable to use these agents for the shortest time possible to prevent unpleasant adverse effects associated with long term use. ${ }^{33}$ Systemic corticosteroids such as hydrocortisone and prednisone can be used in chronic dermatitis to reduce frequency of allergic flares. ${ }^{27}$

\section{The $\mathrm{H}_{1}$-antihistamines}

$\mathrm{H}_{1}$-antihistamines based on pharmacological classification are grouped into different generations. This system of classification is based on their target receptors as well as side-effect profile. ${ }^{34}$ The $\mathrm{H}_{1}$ antihistamines are classified into first generation (older, sedating multi-potent blockers) and second generation (nonsedating, newer) antihistamines. First generation antihistamines include promethazine, chlorpheniramine, dexchlorpheniramine and cyclizine, whilst the second-generation antihistamines include cetirizine (and levocetirizine), loratadine, ebastine, fexofenadine and mizolastine. The most significant difference between the two classes is that first generation $\mathrm{H}_{1}$-antihistamines have the ability to cross the blood brain barrier and the second generation non-sedating $\mathrm{H}_{1}$-antihistamines have very limited ability, if none at all to cross the blood brain barrier. It is also important to note that two generations of systemic (oral and/or parenteral) agents, topical (including intranasal and ophthalmic) $\mathrm{H}_{1}$-antihistamines are available as well. , $^{0,17,32}$

Table I: The differences between first- and second-generation histamine 1 antihistamines ${ }^{35}$

\begin{tabular}{|c|c|c|}
\hline & Older, first-generation $\mathrm{H}_{1}$ antihistamines & Newer, second-generation $\mathrm{H}_{1}$ antihistamines \\
\hline Drug examples & $\begin{array}{l}\text { Promethazine } \\
\text { Chlorpheniramine } \\
\text { Dexchlorpheniramine } \\
\text { Hydroxyzine } \\
\text { Cyclizine }\end{array}$ & $\begin{array}{l}\text { Cetirizine and levocetirizine } \\
\text { Loratadine } \\
\text { Ebastine } \\
\text { Fexofenadine } \\
\text { Mizolastine } \\
\text { Rupatadine }\end{array}$ \\
\hline Frequency & Usually administered in 3-4 daily dosages & Usually administered once or twice a day \\
\hline Mechanism of action & Potent blockers of $\mathrm{H}_{1}, \mathrm{a}_{1}$ and muscarinic receptors & Selective $\mathrm{H}_{1}$-receptor antagonists \\
\hline \multirow[t]{2}{*}{ Blood-brain barrier } & $\begin{array}{l}\text { Cross the blood-brain barrier (lipophilicity, low } \\
\text { molecular weight and lack of recognition by the } \\
\text { p-glycoprotein efflux pump) }\end{array}$ & $\begin{array}{l}\text { Generally, do not cross the blood-brain barrier at } \\
\text { recommended dosages (lipophobicity, high molecular } \\
\text { weight and recognition by the p-glycoprotein efflux pump) }\end{array}$ \\
\hline & $\begin{array}{l}\text { The options for sedation include hydroxyzine, } \\
\text { promethazine and diphenhydramine. However, more } \\
\text { suitable agents may be used in the management of } \\
\text { insomnia }\end{array}$ & $\begin{array}{l}\text { Fexofenadine has the shortest half-life of the systemic } \\
\text { agents. Furthermore, it also does not display any } \mathrm{H}_{1} \text {-receptor } \\
\text { occupancy inside the central nervous system at therapeutic } \\
\text { dosages }\end{array}$ \\
\hline
\end{tabular}

Indications

\begin{tabular}{l} 
Potentially cause side-effects, such as: \\
Sedation \\
Drowsiness and dizziness \\
Hyperactivity (meta-reaction) \\
Insomnia \\
Convulsions \\
Impaired driving performance \\
Fatigue and lassitude (well documented) \\
Side-effects \\
$\begin{array}{l}\text { Anticholinergic side-effects, including a dry mouth, } \\
\text { urinary retention, gastrointestinal upset and appetite } \\
\text { stimulation }\end{array}$ \\
\hline Toxicity \\
Cverdose \\
$\begin{array}{l}\text { A lethal dosage has been identified in infants and young } \\
\text { children }\end{array}$
\end{tabular}

Cetirizine has the greatest likelihood of displaying some degree of $\mathrm{H}_{1}$-receptor occupancy inside the central nervous system, which may result in some level of sedation, albeit at higher-than-recommended dosages

Rupatadine fumarate is approved for the treatment of allergic rhinitis and chronic urticaria for adults and children aged 12 years and older

Do not cause relevant side-effects (sedation, fatigue, hyperactivity and convulsions) in the absence of drug interactions

Minor side-effects include:

Nausea

Light headedness

Drowsiness

Headaches

Agitation and a dry mouth

There have been no reports of serious toxicity

Do not cause fatality in overdose 


\section{First-generation $\mathrm{H}_{1}$-antihistamines}

These older $\mathrm{H}_{1}$-receptor blockers have shown to have sedative and multi-potent receptor blocking abilities. Their ability to cross the blood brain barrier distinguishes them from the newer generation $\mathrm{H}_{1}$ - antihistamines. The chemical structure of the first-generation antihistamines permits them to have a certain degree of non-selectivity, exerting antagonistic effects of an antimuscarinic or anticholinergic, antihistaminergic, $\boldsymbol{\alpha}_{1}$ adrenergic blocking, anti-serotonergic and local anaesthetic nature. Because of their wide range of receptor blocking, the first-generation $\mathrm{H}_{1}$-antihistamines have a variety of indications and uses, which range from allergies and rhino-conjunctivitis, to nausea and vomiting, motion sickness and insomnia. Their effects on multiple receptors on the other hand also has undesirable effects and are not recommended to be used in patients who suffer from glaucoma, benign prostatic hyperplasia and in cardiac patients (i.e. ischemic heart disease, myocardial infarction and congestive heart failure). ${ }^{35}$

\begin{tabular}{|c|c|}
\hline $\begin{array}{l}\text { Receptor antagonistic } \\
\text { interaction }\end{array}$ & Side-effects \\
\hline Histamine-1 receptor & $\begin{array}{l}\text { A reduction in central nervous system } \\
\text { neurotransmission, sedation, reduced } \\
\text { cognitive and neuro-psychomotor } \\
\text { performance, and an increased appetite }\end{array}$ \\
\hline Muscarinic receptor & $\begin{array}{l}\text { Xerostomia, urinary retention and } \\
\text { sinusoidal tachycardia }\end{array}$ \\
\hline a-adrenergic receptor & $\begin{array}{l}\text { QTc-interval prolongation and ventricular } \\
\text { arrhythmias }\end{array}$ \\
\hline Serotonergic receptor & An increased appetite \\
\hline $\begin{array}{l}\text { IKr and other cardiac } \\
\text { channels receptors }\end{array}$ & $\begin{array}{l}\text { QTc-interval prolongation and ventricular } \\
\text { arrhythmias }\end{array}$ \\
\hline
\end{tabular}

The following drugs in this group are of note:

- The options include hydroxyzine, promethazine and diphenhydramine. These drugs are used in the management of insomnia but there are more suitable agents that may be used.

- Cyclizine (syn. meclizine), diphenhydramine, hydroxyzine or promethazine are examples of antiemetic agents. Firstgeneration $\mathrm{H}_{1}$ antihistamines may be very useful in the management of postoperative nausea and vomiting, as well as vertigo.

- Chlorpheniramine is better suited for use in allergic reactions due to its relatively lower sedation levels than the other first generation antihistamines.

It should be noted that these "older" drugs have never been optimally investigated and profiled from a clinical pharmacology perspective.

\section{Second-generation $\mathrm{H}_{1}$-antihistamines}

Second generation $\mathrm{H}_{1}$ antihistamines are relatively newer antihistamines that do not possess the ability to cross the blood brain barrier. They also have no antiemetic, anticholinergic and central nervous system effects unlike the first-generation antihistamines. Drugs like fexofenadine are actively transported into the lumen of the gut, kidney and brain by p-glycoproteins, which restrict their ability to accumulate and cause unwanted side-effects. However, agents such as rifampicin, which induce p-glycoprotein, may increase the clearance of fexofenadine and reduce its efficacy. ${ }^{37}$ Second generation $\mathrm{H}_{1}$-antihistamines are mostly dosed once daily with minimal risk of developing tolerance. The long-term safety of the second-generation $\mathrm{H}_{1}$-antihistamines, cetirizine, desloratadine, fexofenadine, levocetirizine, and loratadine, has been documented in randomised controlled trials lasting 6-18 months in adults, and in children as young as 1-2 years old. ${ }^{38}$

Ophthalmic (eye-drop) preparations include levocabastine, epinastine, olopatadine and ketotifen (the latter also acts as a mast cell stabiliser). Levocabastine, in addition to azelastine, is also available as a nasal spray for use in patients who suffer from allergic rhinitis. ${ }^{39}$

Rupatadine fumarate is a newly launched, second-generation, long-acting histamine antagonist $\left(\mathrm{H}_{1}\right.$-receptor antagonist) and platelet-activating factor receptor inhibitor. Rupatadine fumarate is approved for the treatment of allergic rhinitis and chronic urticaria in adults and children aged 12 years and older. It inhibits the degranulation of mast cells and the subsequent release of cytokines, more specifically of tissue necrotising factor which is available in mast cells and monocytes. ${ }^{40}$

\section{The leukotriene-receptor antagonists}

Examples of leukotriene receptor antagonists include zafirlukast and montelukast. They are competitive antagonists of the cysteinyl leukotriene receptor-1 (cysLT-1). They have the advantage of oral administration. Montelukast is also available as a sprinkle and in a chewable tablet form for the convenient use in pediatrics. Montelukast presents an additional option in the management of seasonal allergic rhinitis in children with asthma. ${ }^{41}$

\section{Conclusion}

Allergic conditions seem to be on a constant rise. Evidence suggests that with inadequate management of an acute allergic disease, a development of a chronic allergic disease in highly probable. Conditions such as rhinitis and sinusitis are examples of conditions that become chronic when acute symptoms are not adequately managed. The use of antihistamines provides symptomatic relief in patients with allergic conditions. The use of first generation antihistamines should be limited to patients who have chronic allergic conditions, have cardiac problems or suffer from benign prostatic hyperplasia due to their stimulation of multiple receptors and tendencies to cause drowsiness. The use of second-generation antihistamines remains the best alternative to chronic allergic conditions except for conditions such as atopic dermatitis and asthma which usually require corticosteroids as long-term therapy. 


\section{References}

1. Tamari M, Tanaka S, Hirota T. Genome-Wide Association Studies of Allergic Diseases. Allergol Int. 2013;;62(1):21-28.

2. Van der Poel L, Warner J. Paediatric allergy in review. Paediatr Child Health. 2012;22(7):259-63.

3. Prescott $\mathrm{S}$. Early-life environmental determinants of allergic diseases and the wider pandemic of inflammatory noncommunicable diseases. J Alergy Clin Immunol. 2013;131(1):23-30.

4. Akdis M, Akdis C. (2013). Mechanisms of allergen-specific immunotherapy: Multiple suppressor factors at work in immune tolerance to allergens. J Alergy Clin Immunol. 2014;133(3):621-31.

5. Bieber T. Atopic dermatitis. Ann Dermatol. 2010;22(2):125-37.

6. Leyva-Castillo J, Li M. Thymic stromal lymphopoietin and atopic diseases. Revue Francaise d'Allergologie. 2014;54(5):364-76.

7. Castro-Rodriguez J, Forno E, Rodriguez-Martinez C, Celedón J. Risk and Protective Factors for Childhood Asthma: What Is the Evidence? J Allergy Clin Immunol: In Practice. 2016;4(6):1111-22.

8. Sinigaglia F, D'Ambrosio D, Rogge L. Type I interferons and the Th1/Th2 paradigm. Dev Comp Immunol. 1999;23(7-9):657-63.

9. Alvarez Zallo N, Aguinaga-Ontoso I, Alvarez-Alvarez I, Guillén-Grima F, Azcona San Julian C. The influence of gender and atopy in the relationship between obesity and asthma in childhood. Allergol Immunopathol. 2017;45(3):227-33.

10. Brunton L, Chabner B, Knollman B. (Eds). Goodman and Gilman's the pharmacological basis of therapeutics. Twelth Edition. New York: McGraw-Hill Medical Publishing Division. 2011.

11. Lu T. Rothenberg M. Diagnostic, functional, and therapeutic roles of microRNA in allergic diseases. J Alergy Clin Immunol. 2013;132(1):3-13.

12. Tang R, Chang J, Chen $\mathrm{H}$. Can probiotics be used to treat allergic diseases? J Chin Med Assoc. 2015;79(3):154-7.

13. Marko M, Pawliczak R. The role of microbiota in allergy development. Alergologia Polska - Polish Journal of Allergology. 2017;.13.

14. Ring J, Brockow K, Ollert M, Engst R. Antihistamines in urticaria. Clin Exp Allergy. 1999;29 (Suppl 1): 31-7.

15. Strachan D. Hay fever, hygiene, and household size. BMJ. 1999;299(6710):1259-60.

16. Brown E, Arrieta M, Finlay B. A fresh look at the hygiene hypothesis: How intestinal microbial exposure drives immune effector responses in atopic disease. Seminars in Immunology. 2013;25(5):379-97.

17. Australasian society of clinical immunology and allergy (2015). Sinusitis and Allergy. Balgowlah. 2015;1-3.

18. Brenner GM, Stevens CW. Pharmacology. Fourth Ed. China: Elsevier Saunders. 2013

19. Matsushita K, Kato Y, Akasaki S, Yoshimoto T. Proallergic cytokines and group 2 innate lymphoid cells in allergic nasal diseases. Japanese Society of Allergology. 2017;64(3):235-40.

20. Okubo K, Kurono $Y$, Ichimura K, Enomoto T, Okamoto $Y$, Kawauchi $H$, et al. Japanese guidelines for allergic rhinitis 2017. Allergol Int. 2017;66(2):205-19.

21. Shah A. Allergic rhinitis, chronic rhinosinusitis and nasal polyposis in Asia Pacific: impact on quality of life and sleep. Asia Pac Allergy. 2014;4(3):131-3.
22. Schubert, M. Allergic fungal sinusitis: pathophysiology, diagnosis and management. Med Mycol. 2009;47(S1):S324-S330.

23. Rosenfeld R, Piccirillo J, Chandrasekhar S, Brook I, Ashok Kumar K, Kramper M, et al. Clinical Practice Guideline (Update): Adult Sinusitis. J Otolaryngol Head Neck Surg. 2015;152(Suppl 2):S1-S39.

24. Möller W, Schuschnig U, Bartenstein P, Meyer G, Häussinger K, Schmid O, et al. Drug Delivery to Paranasal Sinuses Using Pulsating Aerosols. Journal of Aerosol Medicine and Pulmonary Drug Delivery. 2014;27(4):255-63.

25. Bachert C, Zhang L, Gevaert P. Current and future treatment options for adult chronic rhinosinusitis: Focus on nasal polyposis. J Allergy Clin Immunol. 2015;136(6):1431-40.

26. Kennedy J, Borish L. Chronic sinusitis pathophysiology: The role of allergy. Am J Rhinol Allergy. 2013;27(5):367-71.

27. Farrer F. Sinusitis and Allergic Rhinitis. South African Pharmaceutical Journal. 2014; 81(8):11-12.

28. Bae J, Choi Y, Park C, Chung K, Lee K. Efficacy of allergen-specific immunotherapy for atopic dermatitis: A systematic review and meta-analysis of randomized controlled trials. 2017. doi: 10.1016/j.jaci.2013.02.044

29. Bielory BP, O'Brien T, Bielory L. Management of seasonal allergic conjuctivitis: guide to therapy. Acta Ophthalmologica. 2012;90:399-407.

30. Global Initiative for Asthma (GINA). Pocket guide for asthma management and prevention. 2014. Available from: www.ginasthma.org

31. Haahtela T, Holgate S, Pawankar R, Akdis CA, Benjaponpitak S, Caraballo L, et al. WAO Special Committee on Climate Change and Biodiversity. The biodiversity hypothesis and allergic disease: world allergy organization position statement. World Allergy Organization Journal. 2013;6(3):1-19.

32. Rossiter D, ed. South African medicines formulary. 11th ed. Cape Town: Health and Medical Publishing Group; 2014.

33. Schellack G. Pharmacology in clinical practice: application made easy for nurses and allied health professionals. 2nd ed. Claremont: Juta \& Co Ltd. 2010.

34. Derendorf $\mathrm{H}$, Meltzer EO. Molecular and clinical pharmacology of intranasa corticosteroids: clinical and therapeutic implications. Allergy. 2008;63:1292-300.

35. Sadek B, Stark H. Cherry-picked ligands at histamine receptor subtypes. 2017. doi: 10.1016/j.bbrc.2017.07.019

36. Rondón C, Campo P, Togias A, Fokkens WJ, Durham S, Powe DG, et al. Local allergic rhinitis: concept, pathophysiology, and management. J Allergy Clin Immunol. 2012;129(6):1460-7.

37. Criado PR, Criado RFJ, Maruta CW, Filho CDM. Histamine, histamine receptors and antihistamines: new concepts. An Bras Dermatol. 2010;85(2):195-210.

38. Potter PC. Effectiveness and safety of new generation antihistamines in allergenic rhinitis and urticaria. S Afr Fam Pract. 2004;47(1):24-28.

39. Simons FER, Simons KJ. Histamine and $\mathrm{H} 1$-antihistamines: celebrating a century of progress. J Allergy Clin Immunol. 2011;128(6):1139-1150.

40. Williams PB, Crandall E, Sheppard JD. Azelastine hydrochloride, a dual-acting anti-inflammatory ophthalmic solution, for treatment of allergic conjunctivitis. Clin Ophthalmol. 2010:4:993-1001.

41. Mullol J, Bousquet J, Bachert $\mathrm{C}$, et al. Rupatadine in allergic rhinitis and chronic urticaria. Allergy. 2008;63(Suppl 87):5-28.

42. Shamizadeh S, Brockow K, Ring J. Rupatadine: efficacy and safety of a non-sedating antihistamine with PAF-antagonist effects. Allergo J Int.2014;23(3):97-5. 